\title{
Experimental Investigation of a Direct Methanol Fuel Cell with Hilbert Fractal Current Collectors
}

\author{
Jing-Yi Chang, ${ }^{1}$ Yean-Der Kuan, ${ }^{2}$ and Shi-Min Lee ${ }^{3}$ \\ ${ }^{1}$ Ho Tai Development Co., LTD., 12F., No. 143, Fuxing N. Road, Taipei 105, Taiwan \\ ${ }^{2}$ National Chin-Yi University of Technology, No. 35, Lane 215, Section 1, Chung-Shan Road, Taiping District, Taichung 411, Taiwan \\ ${ }^{3}$ Tamkang University, No. 151, Ying-Chuan Road, Tamsui District, New Taipei City 251, Taiwan \\ Correspondence should be addressed to Yean-Der Kuan; ydkuan@ncut.edu.tw
}

Received 21 February 2014; Revised 29 April 2014; Accepted 29 April 2014; Published 20 May 2014

Academic Editor: Lin Liu

Copyright (c) 2014 Jing-Yi Chang et al. This is an open access article distributed under the Creative Commons Attribution License, which permits unrestricted use, distribution, and reproduction in any medium, provided the original work is properly cited.

The Hilbert curve is a continuous type of fractal space-filling curve. This fractal curve visits every point in a square grid with a size of $2 \times 2,4 \times 4$, or any other power of two. This paper presents Hilbert fractal curve application to direct methanol fuel cell (DMFC) current collectors. The current collectors are carved following first, second, and third order Hilbert fractal curves. These curves give the current collectors different free open ratios and opening perimeters. We conducted an experimental investigation into DMFC performance as a function of the free open ratio and opening perimeter on the bipolar plates. Nyquist plots of the bipolar plates are made and compared using electrochemical impedance spectroscopy (EIS) experiments to understand the phenomena in depth. The results obtained in this paper could be a good reference for future current collector design.

\section{Introduction}

A fuel cell is an energy generator that converts chemical energy stored in the fuel directly into electrical energy using a series of electrochemical reactions without any moving parts. The fuel cell system is therefore simple and ideally noiseless. Compared with a traditional combustion engine, the fuel cell has the main advantages that it is clean, efficient, quiet, and simple, with a power and capacity ratio that can be scaled [1]. The direct methanol fuel cell (DMFC) is a prominent potential substitute power source for portable applications. The advantages of the DMFC are operating at near room temperature, using methanol without a bulk transformer, and using convenient combination liquid fuel storage and refueling system. The DMFC is, therefore, suitable for miniature designs and can be easily carried $[2,3]$.

A DMFC usually operates near room temperature. The anode, cathode, and overall reactions are

Anode: $\mathrm{CH}_{3} \mathrm{OH}+\mathrm{H}_{2} \mathrm{O} \longrightarrow 6 \mathrm{e}^{-}+6 \mathrm{H}^{+}+\mathrm{CO}_{2}$

$$
\begin{aligned}
& \text { Cathode: } \frac{3}{2} \mathrm{O}_{2}+6 \mathrm{e}^{-}+6 \mathrm{H}^{+} \longrightarrow 3 \mathrm{H}_{2} \mathrm{O} \\
& \text { Overall: } \mathrm{CH}_{3} \mathrm{OH}+\frac{3}{2} \mathrm{O}_{2} \longrightarrow 2 \mathrm{H}_{2} \mathrm{O}+\mathrm{CO}_{2} .
\end{aligned}
$$

The anode reactants are methanol and water. The oxidation reaction occurs at the anode, which converts the reactants into hydrogen protons, electrons, and carbon dioxide. The hydrogen protons are transported from the anode to the cathode through a polymer electrolyte membrane. The electrons released at the anode are conducted through an external circuit to the cathode. The reduction reaction occurs at the cathode to change protons, electrons, and oxygen into water [4].

In a typical DMFC fuel cell, the bipolar plate is the unit that carries electrons away from the anode to be received at the cathode, distributes the fuel and oxidant within the cell, separates the individual cells in the stack, and assists in water and thermal management. The bipolar plate materials should have high electrical and thermal conductivity, good corrosion resistance, sufficient compressive strength, 
and low density characteristics such that the fuel cell will exhibit high performance and maintain stable operations [5-7].

A DMFC is conventionally stacked in the vertical direction with each bipolar plate serving as the anode in one cell and cathode in the next cell (resulting in multiple cells connected in series). The flow channels inside the bipolar plates are grooved to distribute fuel and collect the electrical charge. PEMFC/DMFC planar interconnection designs have recently been presented in which the architecture alternates between vertical stacking and planar connection in series. This configuration produces better volumetric packaging than the vertical stack, thus giving better design flexibility for portable applications [8]. In planar type DMFCs, such as the planar printed-circuit-board fuel cell module, there is no bipolar plate in the structure. Instead of bipolar plates, this fuel cell has separate current collector components with openings to collect electrons as well as flow boards to distribute fuel among the cells.

Fuel cell performance can be represented by a polarization curve, that is, the cell potential versus current density curve, which reflects the fuel cell activation loss in the low current density range, the ohmic losses in the intermediate current density range, and the concentration loss in the high current density range. The fuel cell polarization curve is determined by measuring the open circuit potential and making the voltage or current measurements at prescribed potential or current intervals [8].

Fractal geometry is mathematically defined in "Hausdorff dimensions," a set of nonintegers, according to the theory proposed by Mandelbrot [9]. Fractal theory describes certain phenomena that are difficult to describe in terms of very fine variations using convectional methods. The main characteristics of a fractal pattern are self-similarity, subdivisibility, and a recursive nature. Fractal patterns have been applied in many engineering fields, such as describing the variations in entropy and heat transfer [10], electronic cooling applications [11], heat sink fins (by Lee et al. [12]), and the automatic polishing path [13].

The first application of fractal theory to the fuel cell was presented by Tüber et al. [14], who applied the "FracTherm" theory in PEM/DMFC flow designs for bipolar plates. Their fractal flow boards were designed as biological fluid channels with a multibranched structure with smooth flow paths. Based on a performance comparison of the fractal, serpentine, and parallel flow fields, the cell with a serpentine flow channel yields better cell performance but has a much greater pressure drop across the channel. Both the multiple-branched fractal and parallel flow fields create a lower pressure drop with similar performance. Chang et al. [15] proposed a type of current collector with a Siepinski carpet fractal geometry. Their current collector design included first and second Siepinski carpet fractal hole arrangements and was compared against the standard hole arrangement. The results showed that the open ratio and perimeter length of the holes are two important factors that affect the performance. A longer total hole perimeter resulted in better cell performance, while a shorter total perimeter length and free open hole ratio led to poor cell performance. Therefore, a longer total perimeter length under the same free open ratio is recommended. Later, Kuan et al. [16] presented a DMFC with Hilbert curve fractal current collectors. They concluded that current collectors with a more uniform opening distribution and higher total opening perimeter length could reduce the anode flow rate effect. A higher total free open ratio and total opening perimeter length in the current collectors could increase the cell performance. In the previous paper, only polarization curves were measured to discuss the cell performance with no further quantitative analysis to explore the impedance behavior caused by the electric charge migration under electrochemical reactions. The current collectors in this work were designed using the Hilbert curve, one of the continuous type fractal geometries. Experiments to measure the polarization curves and Nyquist plots using electrochemical impedance spectroscopy (EIS) were also carried out as part of this study.

\section{Current Collectors with a Hilbert Curve Geometry}

The Hilbert curve fractal is a continuous space-filling curve that fills a square and is typically defined as the limit of a sequence of iteratively defined curves that have only short vertical and horizontal jumps between the points in a square grid with a size of $2 \times 2,4 \times 4,8 \times 8,16 \times 16$ or any other power of 2 . The curves do not have self-intersections or touching points at any stage $[17,18]$.

A DMFC with first, second, and third Hilbert curve current collectors and a standard circular hole arrangement is studied. To simplify the experiments and ensure cell stability, a DMFC with stainless steel 316L (SS316L) current collectors was used because SS316L has the advantage of being easy to machine and lower cost and demonstrates good mechanical properties $[19,20]$. The MEA reactive area is $35 \mathrm{~mm} \times 35 \mathrm{~mm}$, and the size of each current collector is $95 \mathrm{~mm} \times 95 \mathrm{~mm} \times$ $2 \mathrm{~mm}$.

Figure 1 shows a Hilbert curve fractal current collector. The geometric information on the current collectors is shown in Table 1. The widths of the HFCC1, HFCC2, and HFCC3 Hilbert curves were $2.2 \mathrm{~mm}, 2.2 \mathrm{~mm}$, and $1.1 \mathrm{~mm}$, respectively. The total perimeter lengths of the current collector with SRCC, HFCC1, HFCC2, and HFCC3 openings were $614.12 \mathrm{~mm}, 266.90 \mathrm{~mm}, 555.65 \mathrm{~mm}$, and $1117.82 \mathrm{~mm}$, respectively. The total free open areas in the current collectors with the SRCC, HFCC1, HFCC2, and HFCC3 openings were $612.5 \mathrm{~mm}^{2}, 288.75 \mathrm{~mm}^{2}, 606.37 \mathrm{~mm}^{2}$, and $613.59 \mathrm{~mm}^{2}$, respectively. The free open ratios in the current collector with the SRCC, HFCC1, HFCC2, and HFCC3 openings were $50.00 \%, 23.50 \%, 49.40 \%$, and $50.00 \%$, respectively. However, further increasing the free open ratio, that is, making higher Hilbert fractal current order, the carved paths of the current collectors become extremely narrow making the machining difficult. This paper therefore does not discuss fourth or higher fractal order current collectors. 


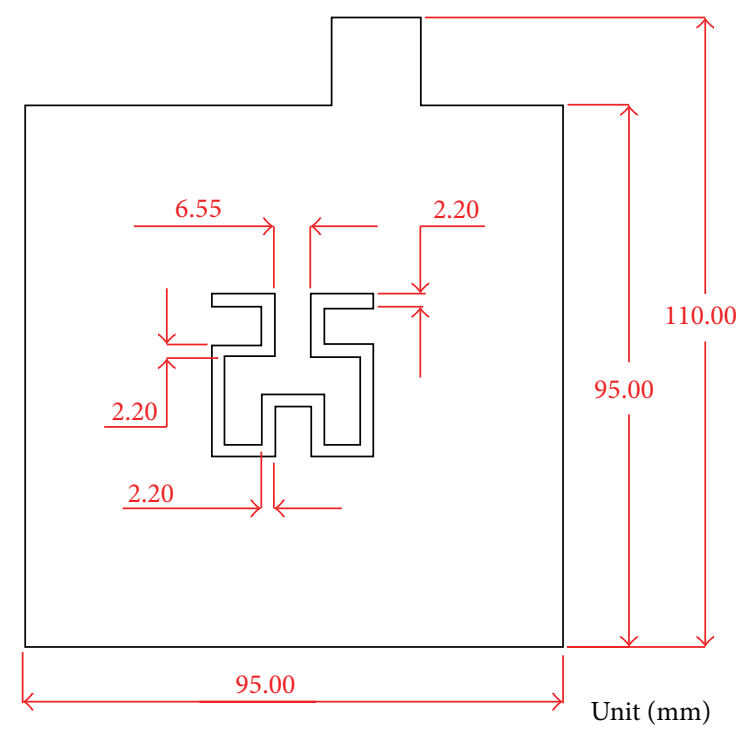

(a) HFCC1

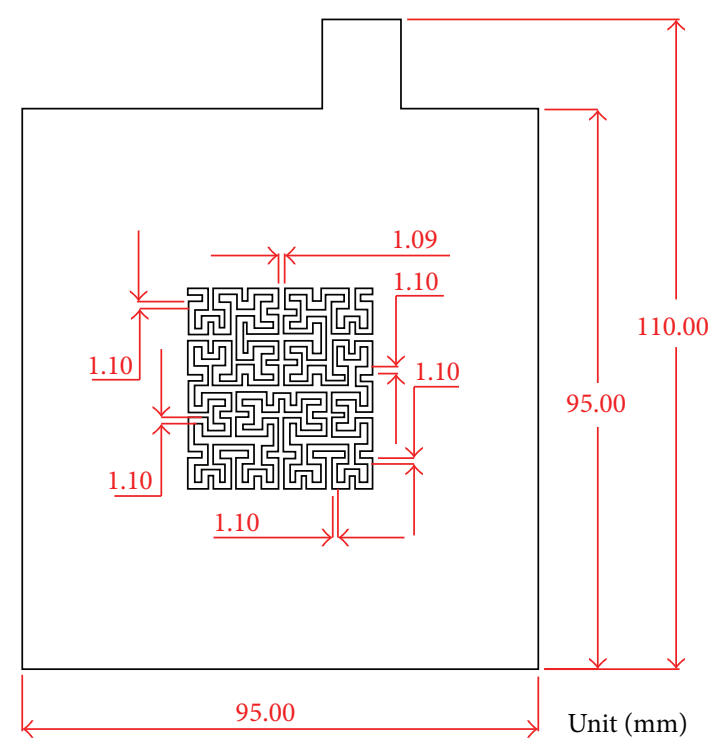

(c) HFCC3

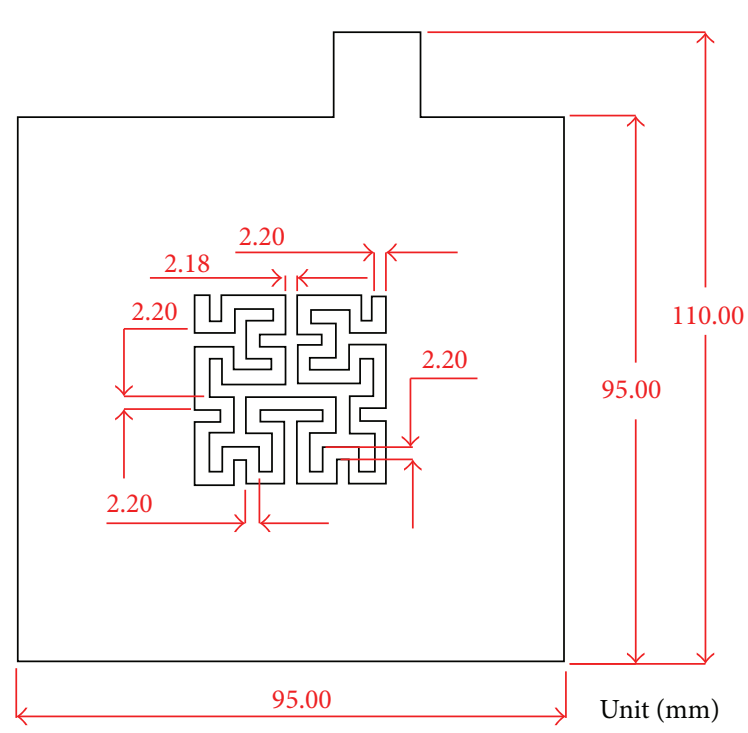

(b) HFCC2

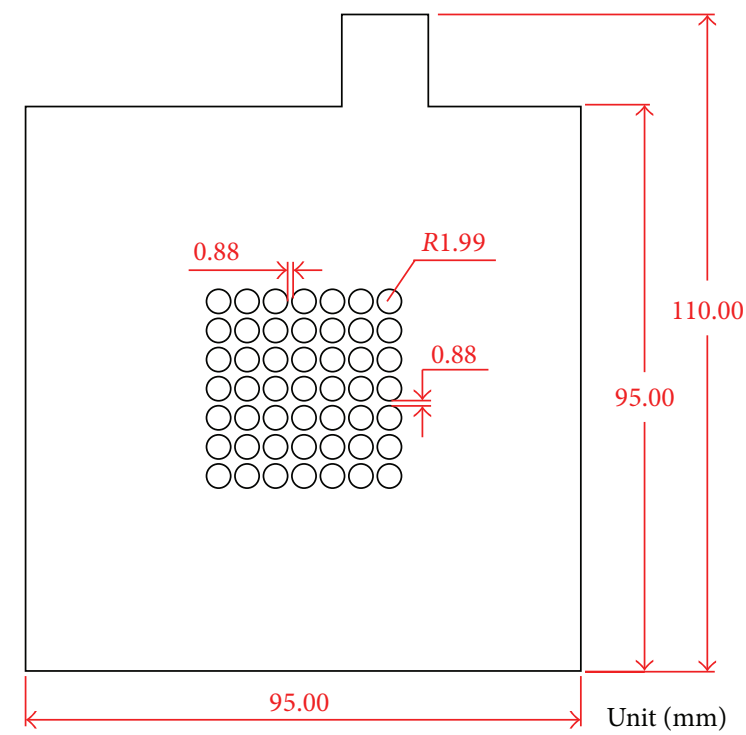

(d) SRCC

FIGURE 1: Hilbert curve fractal current collectors.

\section{Experimental Setup}

A single cell DMFC test fixture was used in this study along with the following components: an anode flow board, gasket, anode current collector, gasket, MEA, gasket, cathode current collector, gasket, and cathode airflow board. The anode and cathode flow boards were made of acrylic. Both the anode and cathode current collectors were made of SS316L. To prevent liquid fuel and air leakage, a gasket was placed between each of the components. The membrane electrode assembly (MEA) was sandwiched between the SS316L plates (Nafion 117 was used as the electrolyte), and a $4 \mathrm{mg} \mathrm{cm}^{-2} \mathrm{Pt}-$ $\mathrm{Ru}$ catalyst was loaded onto the anode and a $4 \mathrm{mg} \mathrm{cm}^{-2} \mathrm{Pt}$ was loaded onto the cathode. The active single cell size in the experimental DMFC was $35 \mathrm{~mm} \times 35 \mathrm{~mm}$. The complete single DMFC test fixture assembly is shown in Figure 2.
Figure 3 shows a schematic diagram of the experimental setup. The anode methanol solution was preheated using a temperature controlled water bath that was fed using a squirm pump. The cathode airflow was driven by an air pump and the flow rate was controlled using an airflow regulator. The DMFC was connected to an electrochemical impedance spectroscopic instrument to make the related measurements. Figure 4 includes a schematic drawing of the physical picture, a circuit diagram, and a Nyquist plot for a simple DMFC impedance model. The symbols are defined as follows: $R_{\Omega}$ : ohmic resistance, $R_{f, \mathrm{~A}}$ : anode Faradaic resistance, $C_{\mathrm{dl}, \mathrm{A}}$ : anode double-layer capacitance, $R_{f, \mathrm{C}}$ : cathode Faradaic resistance, $C_{\mathrm{dl}, \mathrm{C}}$ : cathode double-layer capacitance, $\omega$ : radial frequency, and $Z_{W}$ : Warburg impedance element. Two semicircles are shown in the Nyquist plot. The first loop corresponds to the anode activation kinetics and the second 
TABLE 1: Geometric information on current collectors.

\begin{tabular}{|c|c|c|c|c|}
\hline \multirow{2}{*}{ Factors } & \multicolumn{4}{|c|}{ Geometry } \\
\hline & SRCC & HFCC1 & HFCC2 & HFCC3 \\
\hline Total length of the Hilbert curve path (mm) & None & 131.25 & 275.62 & 557.81 \\
\hline Width of the Hilbert curve path (mm) & None & 2.20 & 2.20 & 1.10 \\
\hline Total perimeter opening length (mm) & 614.12 & 266.90 & 555.65 & 1117.82 \\
\hline Total free open area $\left(\mathrm{mm}^{2}\right)$ & 612.50 & 288.75 & 606.37 & 613.59 \\
\hline Total active MEA area (mm) & 1225 & 1225 & 1225 & 1225 \\
\hline Free open ratio $(\%)$ & $50.00 \%$ & $23.50 \%$ & $49.40 \%$ & $50.00 \%$ \\
\hline
\end{tabular}

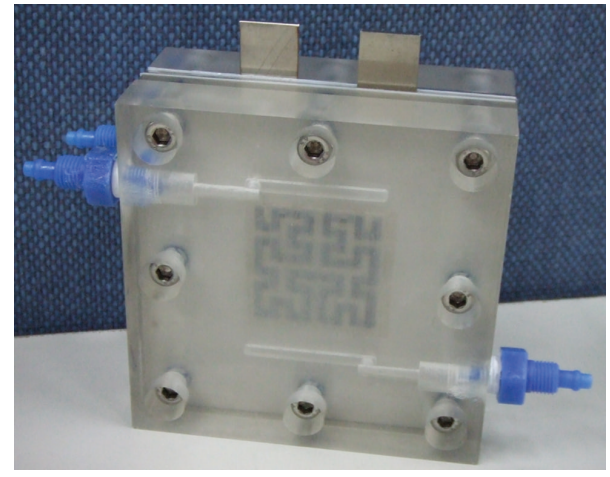

FIGURE 2: Single cell DMFC assembly.

loop corresponds to the cathode activation kinetics. At high frequencies, the real-axis intercept corresponds to the ohmic resistance. The diameter of the first loop gives $R_{f, \mathrm{~A}}$, and the diameter of the second loop gives $R_{f, \mathrm{C}}$. At low frequencies the diagonal line is due to mass transport which is enabled by the infinite Warburg impedance. The impedance response characterization depends on the operating voltage. The activation kinetics dominate and the Faradaic resistance $\left(R_{f}\right)$ is large for high voltages. The activation loops decrease due to the decreasing value of $R_{f}$ at the intermediate operating voltage range. The activation loops would continue to decrease, but the diagonal Warburg response might occur at low frequencies because of the mass transport effect in the low operating voltage range [10]. This paper only discusses the characterization at high and intermediate operating voltage ranges. The low operating voltage range is not covered because a DMFC should generally operate above the concentration polarization range.

\section{Results and Discussion}

In all of these experiments the environmental conditions were kept at room temperature and humidity $(\sim 60 \% \mathrm{RH})$. The anode was supplied with a $55^{\circ} \mathrm{C}$ and $2 \mathrm{M} \mathrm{MeOH} / \mathrm{DI}$ watermethanol solution. In our previous study the results indicated that the performances are close under different DMFC anode flow rates with standard circular hole current collectors. Therefore, this study maintained the anode flow rate at $15 \mathrm{cc}$ $\mathrm{min}^{-1}$ and cathode airflow rate of $1000 \mathrm{cc} \mathrm{min}{ }^{-1}$ throughout the study [16].
Figure 5 shows a comparison of the polarization curves for the DMFC at a $15 \mathrm{cc} \mathrm{min}^{-1}$ anode flow rate. The DMFC with HFCC3 showed the best cell performance, the DMFC with HFCC2 showed the second best performance, the DMFC with SRCC showed the third best cell performance, and the HFCC1 had the worst cell performance.

Figure 6 is a comparison of the Nyquist plots obtained using the EIS measurements at $0.5 \mathrm{~V}$ for the DMFCs with different current collectors. The DMFC with HFCC1 showed the largest cell impedance response which leads to the worst cell performance. The DMFC with SRCC showed the second largest cell impedance response. The DMFC with HFCC2 showed the third largest cell impedance response, and the DMFC with HFCC3 showed the lowest impedance response.

Figure 7 shows a comparison of the Nyquist plots obtained by the EIS measurements at $0.4 \mathrm{~V}$ for the DMFCs with different current collectors. The DMFC with HFCC1 showed a significantly larger impedance response than the others, which leads to the worst cell performance. The DMFC with SRCC showed the second largest impedance response, but it was still much lower than the DMFC with HFCC1. The DMFC with HFCC2 showed the third largest impedance response, and the DMFC with HFCC3 showed the lowest impedance response.

The DMFC current collectors with a low free open ratio and short total perimeter opening length, such as HFCC1, showed significant large cell impedance, thus resulting in the worst cell performance. When a high free open ratio and long total perimeter opening length were used, the significant cell impedance dropped at $0.4 \mathrm{~V}$ (i.e., the ohmic impedance was obviously reduced), and the cell impedance showed a drop at $0.5 \mathrm{~V}$ (i.e., the activation impedance was reduced, but not as much as the change at $0.4 \mathrm{~V}$ ).

The experimental results do not show the long tails up as in Figure 5 for the EIS measurements in Figures 6 and 7. At the low AC frequency range, if the electrode receives an applied voltage, the reaction time becomes longer and the reactants at the electrode surfaces react completely leading to insufficient fuel. The mass polarization effect might then become significantly prominent, causing the long tails up as shown in Figure 5. However, this phenomenon did not occur in the experiments such that there were no long tails up in Figures 5 and 7 .

The total free open ratio is almost the same for the DMFC current collectors with HFCC2, HFCC3, and SRCC. The HFCC3 has a significantly longer total perimeter opening 


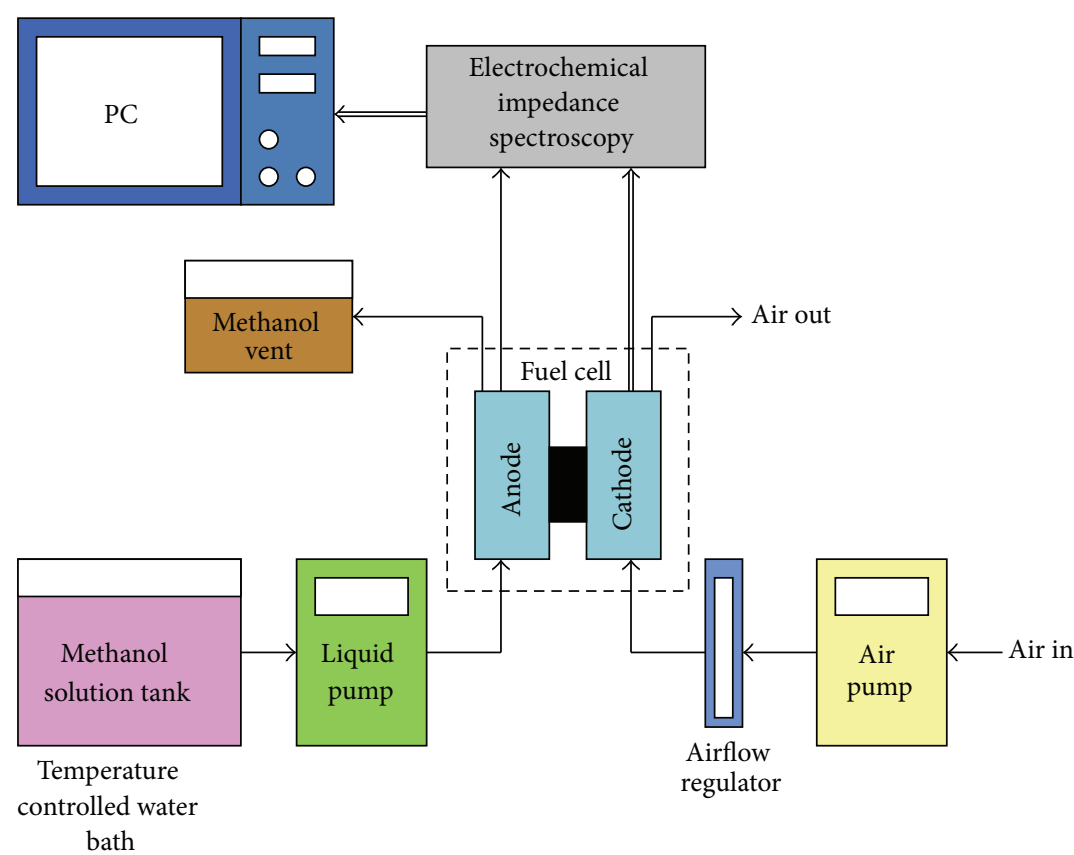

FIgURE 3: Experimental setup.

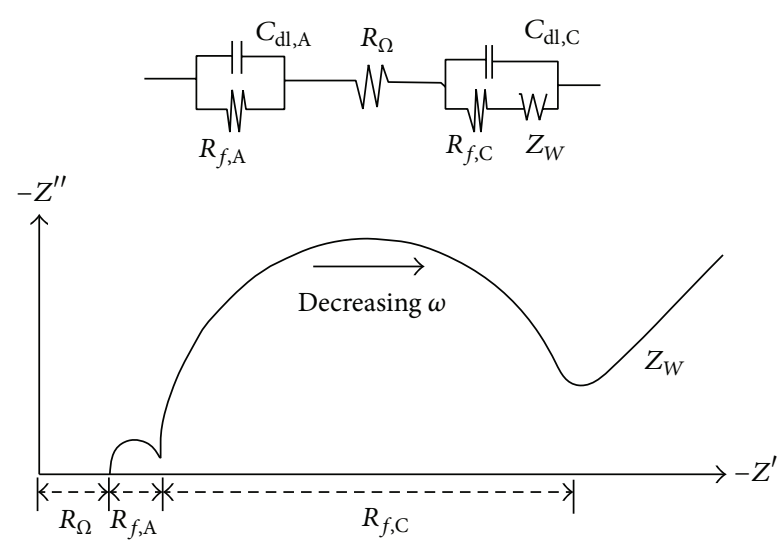

Figure 4: Schematic drawing of Nyquist plot and circuit diagram for a simple fuel cell impedance model.

length. The HFCC2 and SRCC have the close total perimeter length of opening, but the SRCC is slightly longer than HFCC2. Through a comparison of the DMFC, HFCC2, and SRCC, we found that the HFCC2 showed slightly lower cell impedance than the SRCC at $0.5 \mathrm{~V}$; that is, the activation impedance was slightly lower. In addition, the HFCC2 had lower cell impedance than the SRCC at $0.4 \mathrm{~V}$; that is, the ohmic impedance was obviously lower. Therefore, at the close free open ratio and total perimeter opening length, the DMFC with continuous openings reduced the ohmic impedance with slightly smaller activation impedance than the unit with the separate openings. Thus, the DMFC with the continuous opening performed better. Under the same free open ratio the current collector with HFCC3 has a much longer total perimeter opening length. Through a com-parison of the

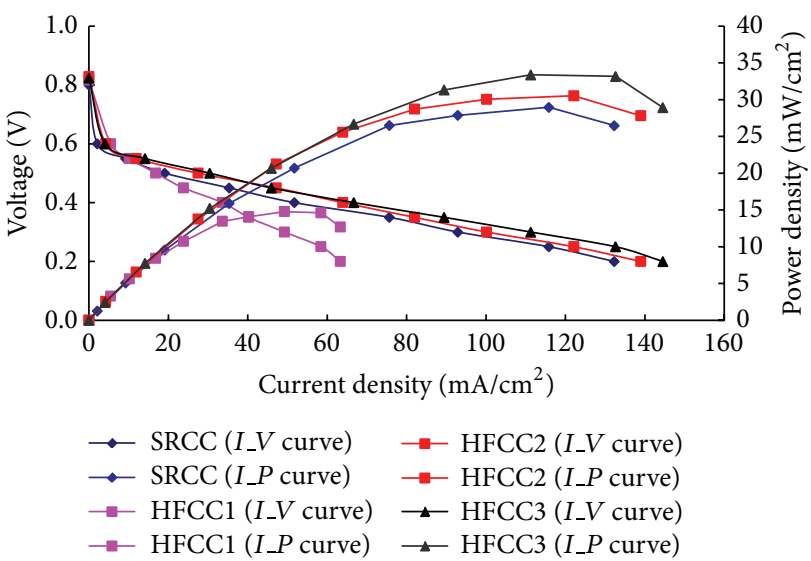

FIGURE 5: Performance comparison of the DMFC with different current collectors.

DMFC with the HFCC3 and HFCC2, the HFCC3 had lower cell impedance values at both $0.5 \mathrm{~V}$ and $0.4 \mathrm{~V}$. Therefore, continuously increasing the total perimeter opening length would reduce both the activation and ohmic impedance and result in better cell performance.

According to the experimental results, the DMFC with HFCC1 shows the lowest cell performance and highest impedance. The HFCC1 geometrical design has the smallest total free opening ratio and the shortest total perimeter opening length. At the $0.5 \mathrm{~V}$ and $0.4 \mathrm{DC}$ load there is larger electric charge resistance during the DMFC electrochemical reaction process, thus increasing the internal resistance. Therefore, the DMFC shows lower cell performance and higher resistance. The total free opening ratio of HFCC3, HFCC2, and SRCC is designed about 50\%; the HFCC3 has 


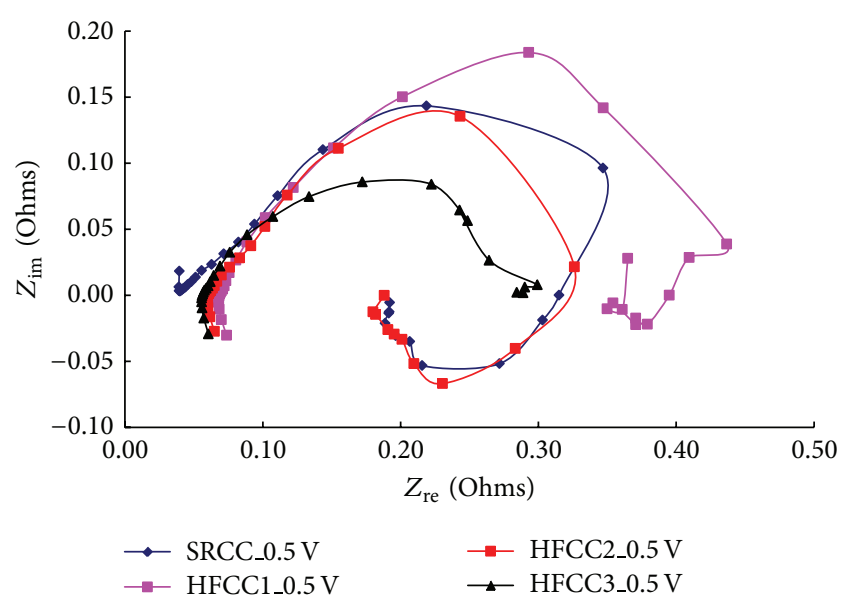

FIGURE 6: Comparison of the Nyquist plots at $0.5 \mathrm{~V}$ for the DMFC with different current collectors.

the longest total perimeter opening length, SRCC has the second longest, and HFCC2 has the shortest. The polarization measurements show that the DMFC with the HFCC 3 current collectors has the highest cell performance, with the HFCC1 having the second and with the SRCC having the lowest. The EIS experiments show that the DMFC with the HFCC3 current collectors has the lowest impedance, with HFCC2 the second and with SRCC the highest. The main reason the DMFC with HFCC2 currents has higher cell performance and lower impedance is because the HFCC2 is a continuous type of geometry, which could help supply the fuel and drain the production more smoothly. In addition, the free opening distribution for the HFCC2 could make the reactants at both the anode and cathode more uniformly distributed into the diffusion layers allowing the reactants to drain out more smoothly. As the HFCC2 geometry is more uniformly and systematically divided, it provides longer total current collector perimeter opening length than SRCC under the same reaction area. The electric charge distribution is then distributed more uniformly and the inner resistance reduced. As the HFCC3 has the longest total perimeter opening length under the approximately same total free opening ratio, the DMFC with HFCC 3 current collectors shows the highest cell performance and lowest cell resistance.

\section{Conclusions}

This paper investigated a DMFC design with Hilbert curve fractal openings. The DMFC with HFCC1, which had the smallest free area ratio and the shortest total perimeter opening length, had the worst cell performance and the largest impedance at both $0.4 \mathrm{~V}$ and $0.5 \mathrm{~V}$. Increasing both the free area ratio and total perimeter opening length could significantly reduce the impedance at $0.4 \mathrm{~V}$, that is, ohmic impedance, and also reduce the impedance at $0.5 \mathrm{~V}$ (activation impedance), although this effect is expected to be smaller than at $0.4 \mathrm{~V}$. Under the same free open ratio and total perimeter opening length, the DMFC with continuous openings could help to reduce the ohmic impedance with

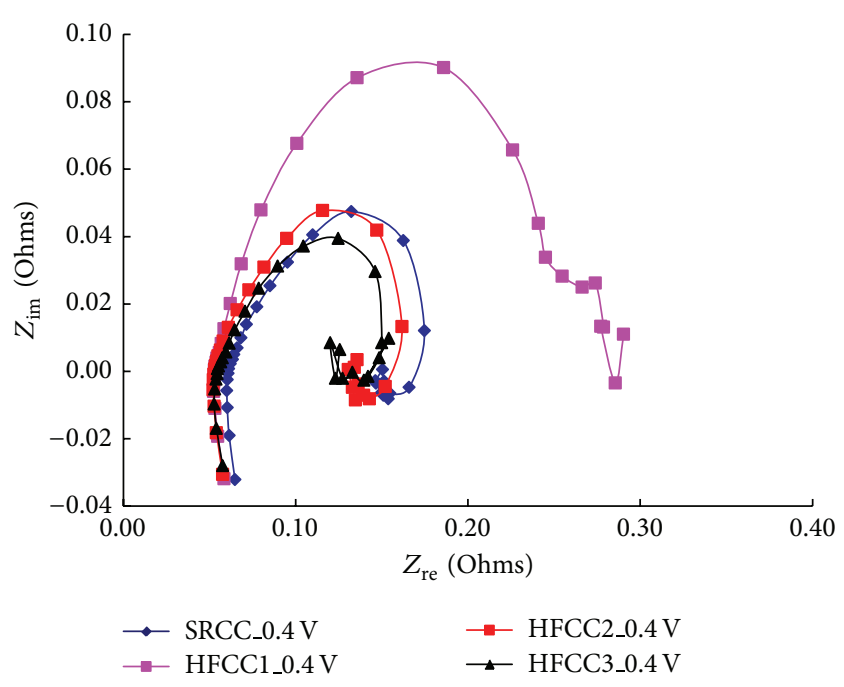

FIgURE 7: Comparison of the Nyquist plots at $0.4 \mathrm{~V}$ for the DMFC with different current collectors.

slightly less activation impedance. A further increase in the total perimeter opening length, such as in the case of the DMFC with HFCC3 (which contains the longest total perimeter opening length and free open ratio), could continuously reduce the activation and ohmic impedances, leading to better cell performance.

\section{Conflict of Interests}

The authors declare no conflict of interests.

\section{Acknowledgment}

The authors would like to acknowledge financial support from the National Science Council of Taiwan (NSC-2221-E167-030 and NSC 101-2628-E-167-001-MY3).

\section{References}

[1] R. O'Hayre, S. W. Cha, W. Colella, and F. B. Prinz, Fuel Cell Fundamentals, John Wiley \& Sons, Hoboken, NJ, USA, 2006.

[2] J. Larminie and A. Dicks, Fuel Cell Systems Explained, John Wiley \& Sons, Chichester, UK, 2nd edition, 2003.

[3] G. Apanel and E. Johnson, "Direct methanol fuel cells-ready to go commercial?" Fuel Cells Bulletin, vol. 2004, no. 11, pp. 12-17, 2004.

[4] J.H. Hirschenhofer, D.B. Stauffer, R.R. Engleman, and M.G. Klett, Fuel Cell Handbook, E\&G Services, Parson Inc., Science Applications International Corporation, Morgantown, WVa, USA, 5th edition, 2000.

[5] T. Schultz, S. Zhou, and K. Sundmacher, "Current status of and recent developments in the direct methanol fuel cell," Chemical Engineering \& Technology, vol. 24, no. 12, pp. 1223-1233, 2001.

[6] H. Tsuchiya and O. Kobayashi, "Mass production cost of PEM fuel cell by learning curve," International Journal of Hydrogen Energy, vol. 29, no. 10, pp. 985-990, 2004. 
[7] A. Hermann, T. Chaudhuri, and P. Spagnol, "Bipolar plates for PEM fuel cells: a review," International Journal of Hydrogen Energy, vol. 30, no. 12, pp. 1297-1302, 2005.

[8] F. Barbir, PEM Fuel Cells, Elsevier, Burlington, Mass, USA, 2005.

[9] B. B. Mandelbrot, The Fractal Geometry of Nature, W. F. Freeman, San Francisco, Calif, USA, 1982.

[10] D. J. Lee and W. W. Lin, "Second law analysis on fractal-like fin under crossflow, AIChE Journal, vol. 41, no. 10, pp. 2314-2317, 1995.

[11] G. Ledezma, A. Bejan, and M. Errera, "Contractual tree networks for heat transfer," Journal of Applied Physics, vol. 82, pp. 89-100, 1997.

[12] S. Lee, Y. Wang, and C. Chen, "Thermal performance of novel fractal heat sink fins," Journal of the Chinese Society of Mechanical Engineers, vol. 25, pp. 547-556, 2004.

[13] C. A. Chen, Y. Juang, and W. Lin, "Generation of fractal toolpaths for irregular shapes of surface finishing areas," Journal of Materials Processing Technology, vol. 127, no. 2, pp. 146-150, 2002.

[14] K. Tüber, A. Oedegaard, M. Hermann, and C. Hebling, "Investigation of fractal flow-fields in portable proton exchange membrane and direct methanol fuel cells," Journal of Power Sources, vol. 131, no. 1-2, pp. 175-181, 2004.

[15] J. Chang, Y. Kuan, S. Lee, and S. Lee, "Characterization of a liquid feed direct methanol fuel cell with Sierpinski carpets fractal current collectors," Journal of Power Sources, vol. 184, no. 1, pp. 180-190, 2008.

[16] Y. Kuan, J. Chang, S. Lee, and S. Lee, "Characterization of a direct methanol fuel cell using Hilbert curve fractal current collectors," Journal of Power Sources, vol. 187, no. 1, pp. 112-122, 2009.

[17] R. Crownover, Introduction to Fractals and Chaos, Jones and Bartlett Publishers, Boston, Mass, USA, 1995.

[18] H. Peitgen, H. Jurgens, and D. Saupe, Chaos and Fractals New Frontiers of Science, Springer, New York, NY, USA, 1992.

[19] R. C. Makkus, A. Janssen, F. A. de Bruijn, and R. Mallant, "Stainless steel for cost-competitive bipolar plates in PEMFCs," Fuel Cells Bulletin, vol. 3, no. 17, pp. 5-9, 2000.

[20] J. Wind, R. Späh, W. Kaiser, and G. Böhm, "Metallic bipolar plates for PEM fuel cells," Journal of Power Sources, vol. 105, no. 2, pp. 256-260, 2002. 

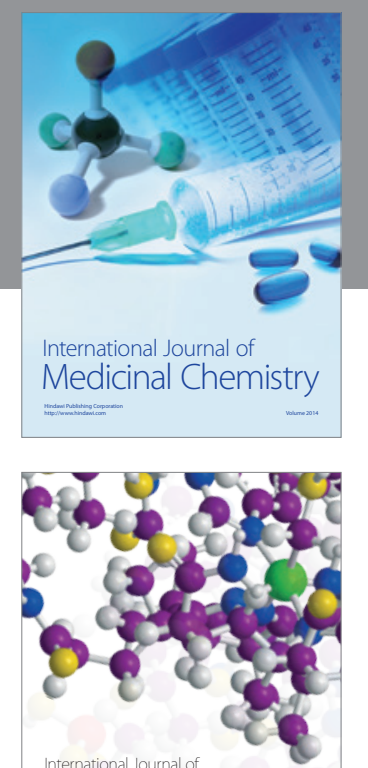

\section{Carbohydrate} Chemistry

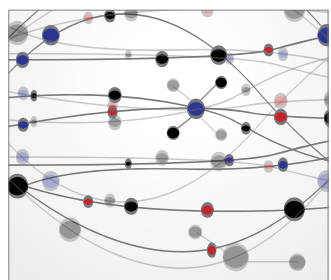

The Scientific World Journal
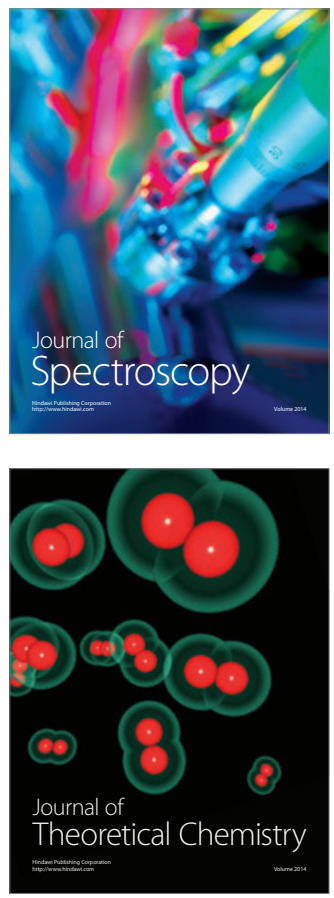
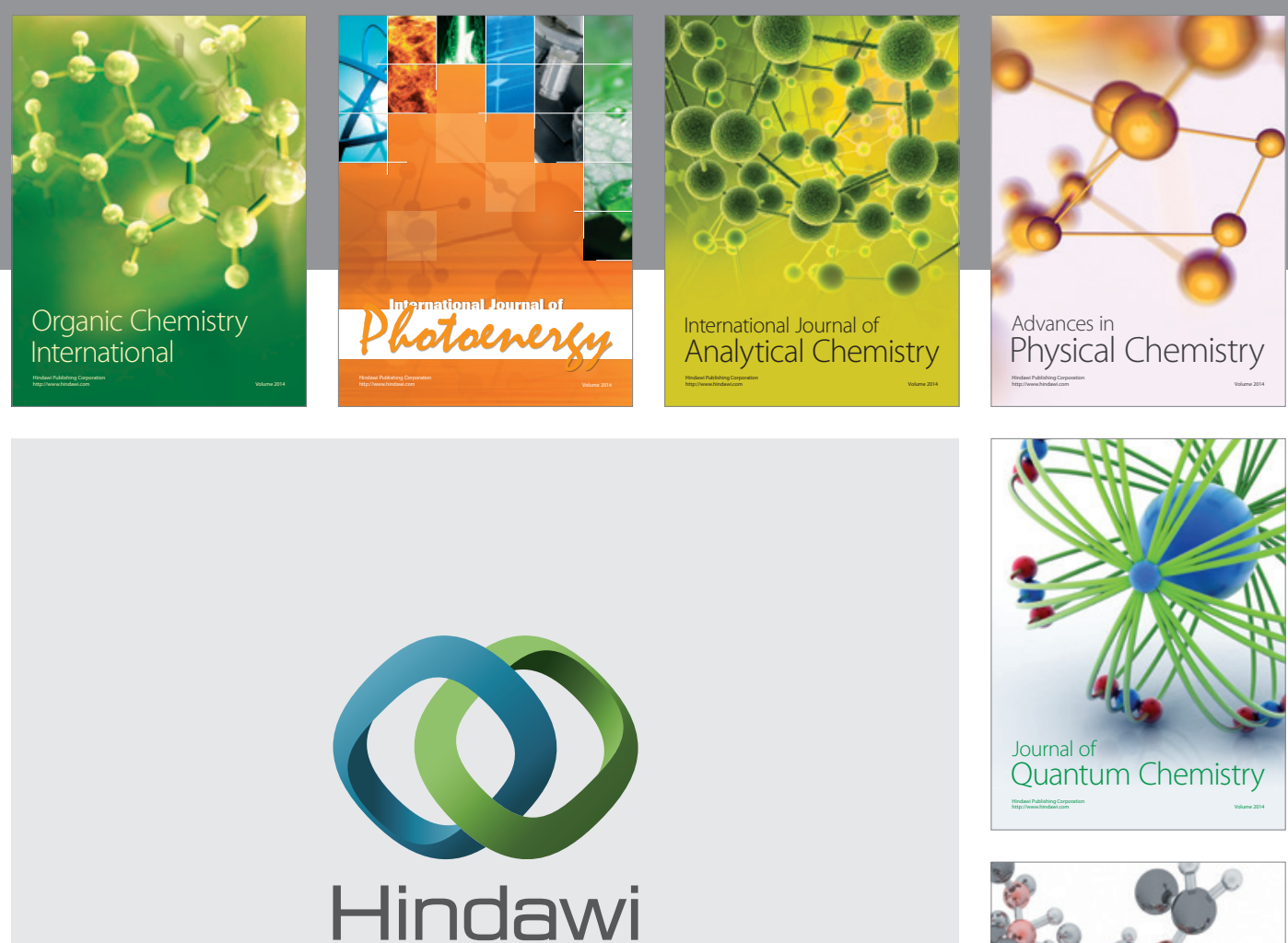

Submit your manuscripts at

http://www.hindawi.com

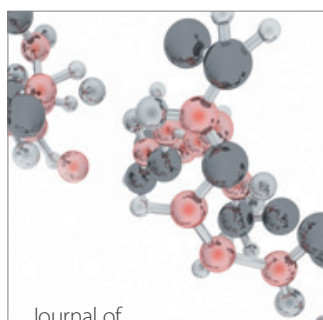

Analytical Methods

in Chemistry

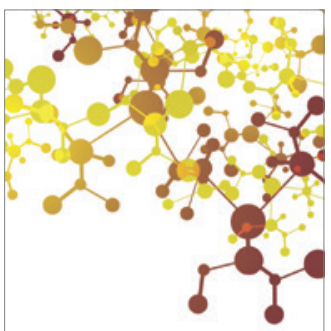

Journal of

Applied Chemistry

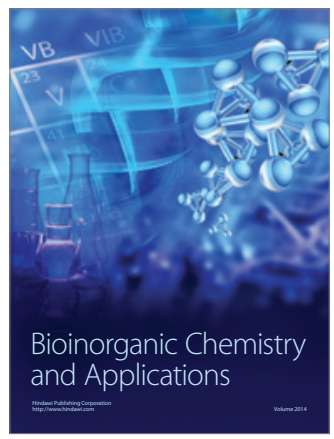

Inorganic Chemistry
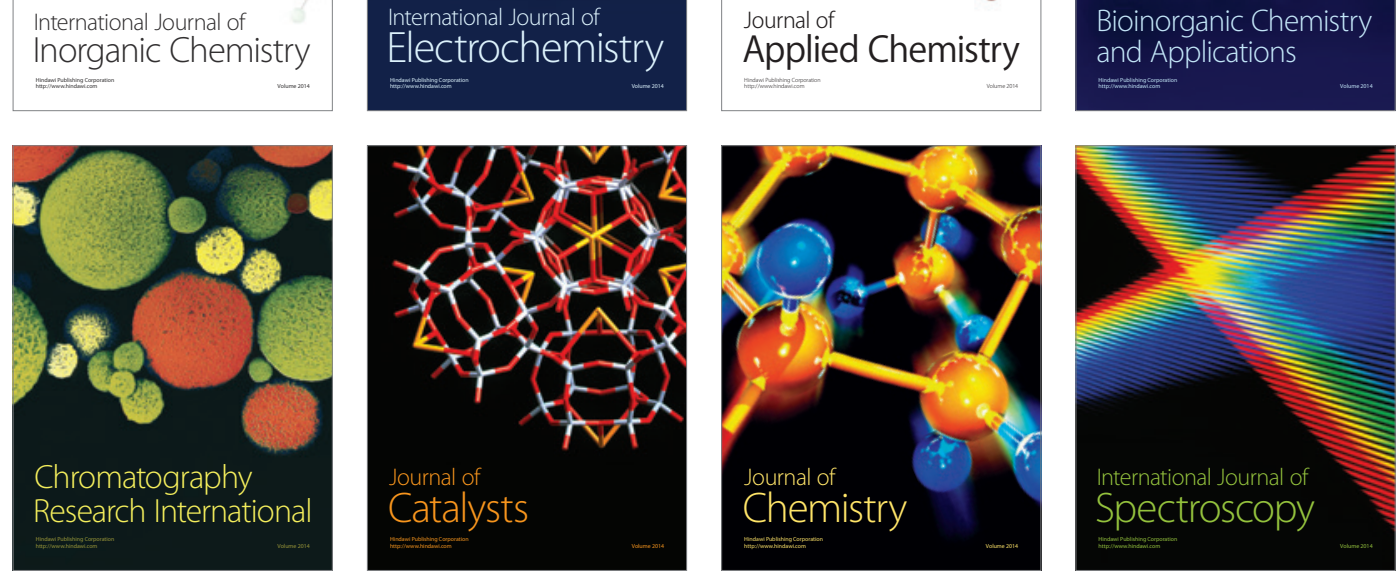